\title{
Opicapona \\ - o Primeiro \\ Inibidor da COMT \\ de Terceira Geração
}

Miriam Colaço*
Marcos Bento
Rúben Guerreiro

\begin{abstract}
Opicapone - The First COMT Inhibitor from the Third Generation. Levodopa is the most commonly used drug to treat Parkinson's disease. This drug must be co-administered with enzyme inhibitors that metabolize it before reaching the brain, including catechol O-methyltransferase (COMT) inhibitors. A drug has been recently launched to inhibit this enzyme, which is safer and more effective than the previous ones and whose active ingredient is opicapone (OPC). It presents an optimized pharmacokinetic and pharmacodynamic profile, in which OPC and its metabolites are rapidly excreted, however the high durability of the COMT-OPC complex allows a single daily administration.
\end{abstract}

A levodopa é o fármaco mais utilizado no tratamento da doença de Parkinson. Este fármaco tem de ser coadministrado com inibidores de enzimas que o metabolizam antes de chegar ao cérebro, entre os quais estão os inibidores da catecol O-metiltransferase (COMT). Recentemente foi desenvolvido um fármaco para inibir esta enzima, que é mais seguro e eficaz que os anteriores e cujo princípio ativo é a opicapona (OPC). Denota-se um perfil farmacocinético e farmacodinâmico otimizado, no qual a OPC e os seus metabolitos são rapidamente excretados, mas a elevada durabilidade do complexo COMT-OPC permite uma única administração diária.

\footnotetext{
A doença

A doença de Parkinson (DP) é uma doença neurodegenerativa que afeta cerca de 5,2 milhões de pessoas em todo o mundo. Na maioria dos casos, a patologia surge esporadicamente, pelo que a idade média para o aparecimento dos primeiros sintomas da DP é aos 65 anos. Contudo, cerca de 5 a 10\% dos pacientes são diagnosticados antes dos 40 anos uma vez que esta doença também pode surgir devido a fatores genéticos [1].

O desenvolvimento desta patologia incurável advém da progressiva degeneração e morte dos neurónios dopaminérgicos da substância negra (porção do mesencéfalo). A concomitante redução da libertação do neurotransmissor dopamina (DA) afeta a via nigro-estriatal, levando à perda de algumas funções motoras como bradicinesia, tremores, rigidez ou perda de olfato e paladar. Alguns distúrbios psiquiátricos
}

(depressão, ansiedade, demência, insónias) também estão associados a pacientes com DP [1].

Muitos são os mecanismos que levam ao despoletar e à progressão da doença, alguns dos quais ainda não são conhecidos ou totalmente compreendidos [2].

Uma importante característica histopatológica da DP é a acumulação de corpos de Lewy, que são agregados proteicos constituídos maioritariamente por $\alpha$-sinucleína (aparentemente envolvida no controlo de processos das membranas sinápticas). A sua liberdade conformacional permite a ligação a membranas e a formação de oligómeros citotóxicos, causando disrupção de membranas (formação de poros), disfunção mitocondrial, stresse oxidativo e do retículo endoplasmático e comprometimento do proteassoma (Figura 1) [3]. 


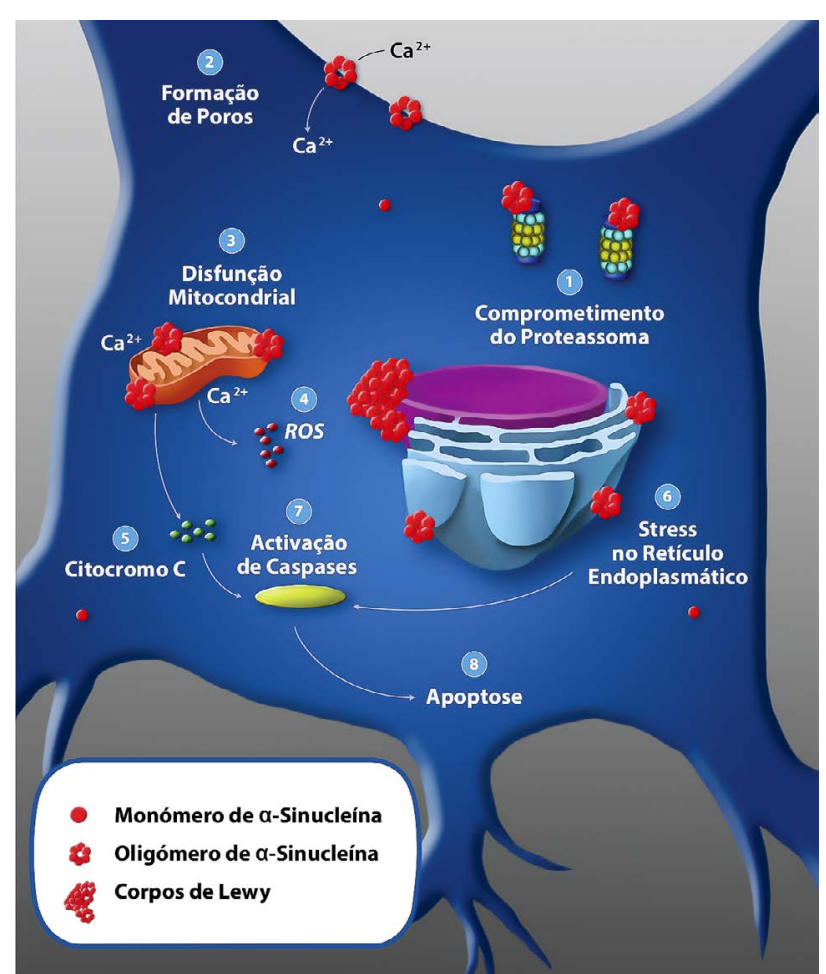

Figura 1 - Mecanismos de toxicidade da $\alpha$-sinucleína que culminam em morte celular programada (adaptada da referência [3])

No entanto, nalgumas formas hereditárias da doença podem não se formar corpos de Lewy. Um conhecido exemplo é quando a doença é causada por mutações no gene da Parkina, (uma E3 ubiquitina ligase), que resultam em disfunção mitocondrial e consequente perda neuronal [2].

\section{Fármacos existentes no mercado}

A Levodopa (L-DOPA), o principal fármaco utilizado no tratamento da DP, é um aminoácido não natural, o que lhe permite atravessar a barreira hematoencefálica através de um transportador de aminoácidos. Uma vez no cérebro, a levodopa é convertida em DA pela enzima descarboxilase de L-aminoácidos aromáticos (AADC) (Figura 2). Contudo, apenas $1 \%$ da dose oral de L-DOPA alcança o cérebro. Assim, é necessário coadministrar um inibidor da AADC periférica, como carbidopa ou benserazida [4].<smiles>COc1ccc(CC(N)C(=O)O)cc1OCC(=O)Oc1cc(CCN)cc(O)c1O</smiles>

Figura 2 - Ação das enzimas descarboxilase de L-aminoácidos aromáticos (AADC) e catecol-O-metiltransferase (COMT) na metabolização da levodopa.
No entanto, após longos períodos de terapia, muitos pacientes começam a apresentar flutuações, isto é, os sintomas reaparecem antes da administração da dose seguinte (período off). Nestes casos, além da combinação anterior pode ainda ser coadministrado um inibidor da catecol O-metiltransferase (COMT), uma vez que esta converte cerca de $90 \%$ da L-DOPA em 3-0-metil-levodopa (3-OMD) (Figura 2), que ainda compete com a L-DOPA ao nível do transporte para o cérebro por continuar a ser um aminoácido [4].

Em junho de 2016, entrou no mercado um novo fármaco da BIAL chamado Ongentys, cujo princípio ativo é a opicapona (OPC ou BIA 9-1067, Figura 3), um inibidor reversível da COMT de terceira geração. Este foi desenvolvido para colmatar os problemas associados aos principais inibidores de segunda geração previamente existentes (Figura 3): entacapona (eficácia reduzida devido à sua baixa biodisponibilidade e fraca inibição) e tolcapona (atravessa a barreira hematoencefálica, mas é hepatotóxico) [4].<smiles>CCN(CC)C(=O)/C(C#N)=C/c1cc(O)c(O)c([N+](=O)[O-])c1</smiles>

Entacapona<smiles>Cc1ccc(C(=O)c2cc(O)c(O)c([N+](=O)[O-])c2)cc1</smiles>

Tolcapona

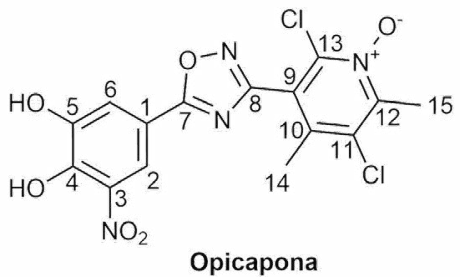

Figura 3 - Estruturas dos principais inibidores da COMT de segunda geração e estrutura da opicapona (OPC).

\section{Alvo biológico}

A atividade fisiológica da COMT (EC 2.1.1.6) segue a via de inativação metabólica de neurotransmissores endógenos de catecol e substâncias xenobióticas. A COMT é intracelular (podendo ser solúvel, S-COMT, ou membranar, MB-COMT) e pode ser encontrada em tecidos periféricos (principalmente nos rins) ou no sistema nervoso central, onde se encontra uniformemente distribuída, mas possui menor atividade [5].

Esta enzima é uma transferase dependente de magnésio, que catalisa a transferência de grupos metilo do cofator S-adenosil-L-metionina (AdoMet ou SAM) para substratos catecólicos, resultando na formação de produtos mono-O-metilados e $\mathrm{S}$-adenosil-L-homocisteína (AdoHcy ou SAH) $[5,6]$.

0 desenho racional de inibidores para este alvo biológico tem por base a cocristalização da forma 
solúvel da COMT com os seus cofatores e um ligando de elevada afinidade (Figura 4) [6].

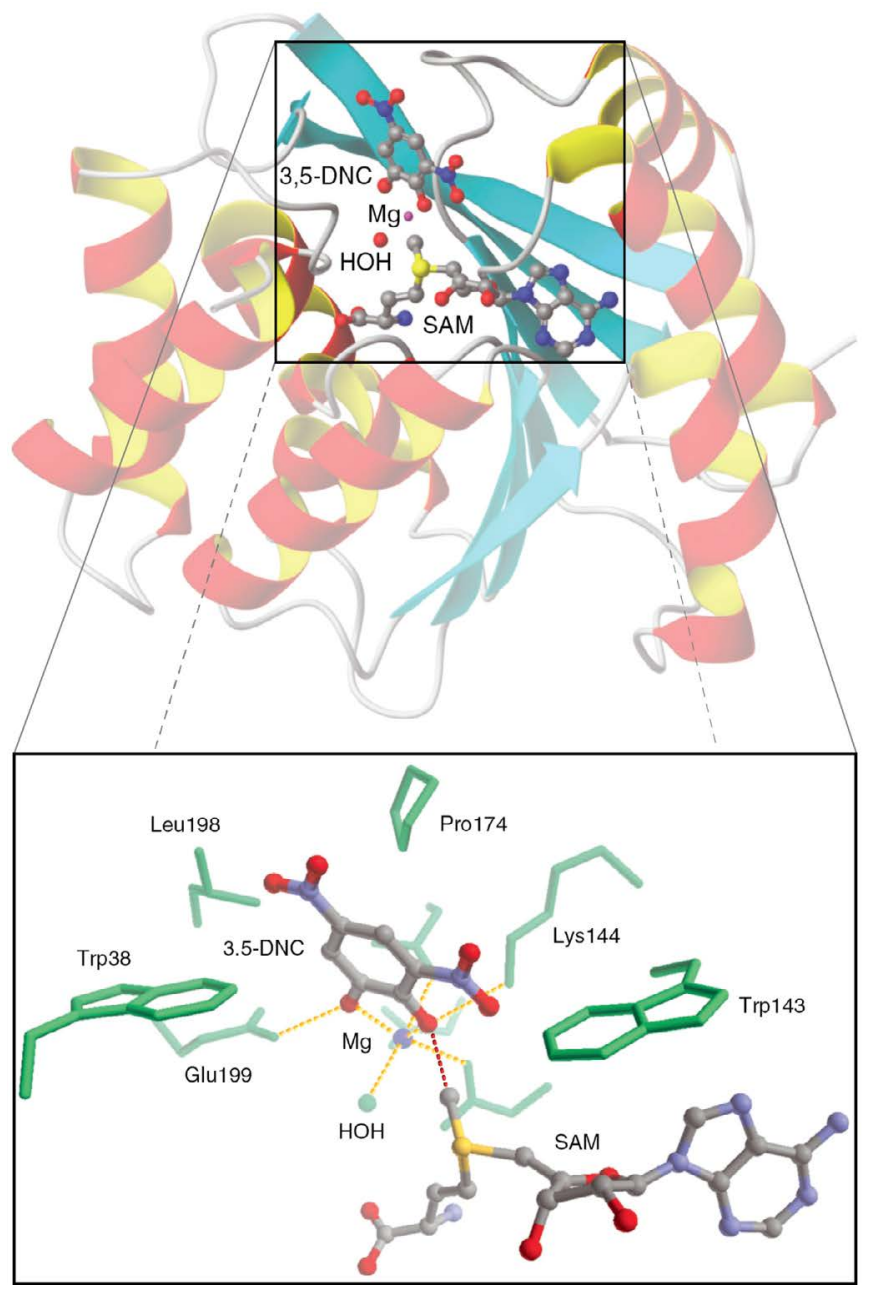

Figura 4 - Representação esquemática da estrutura tridimensional e ampliação do centro catalítico da enzima S-COMT de rato com o ligando 3,5-dinitrocatecol e os cofatores SAM e ião $\mathrm{Mg}^{2+}$. As ligações de coordenação com o ião metálico e as pontes de hidrogénio estabelecidas entre os grupos hidroxilo do ligando catecólico e os resíduos da proteína estão representados com um tracejado amarelo e a ligação covalente que se formaria por catálise enzimática está representada com o tracejado vermelho (adaptada da referência [7]).

A coordenação com o $\mathrm{Mg}^{2+}$ reduz o $\mathrm{p} K_{\mathrm{a}}$ do catecol facilitando a captura do protão mais acídico pela Lys144. De seguida dá-se o ataque nucleofílico do ião fenolato ao catião de enxofre do SAM com transferência do grupo metilo para o catecol através de um mecanismo do tipo $\mathrm{S}_{\mathrm{N}} 2$ (sem formação de um intermediário com a enzima metilada) [7].

\section{Desenvolvimento do inibidor}

0 processo de desenvolvimento de um novo inibidor para a COMT teve início com um screening de compostos catecólicos através de testes in vitro em homogenatos de fígado de rato, tendo-se obtido o composto guia 2,4-[4-(4-clorofenil)-5-metil-1H-pirazol-3-il]benzeno-1,2,3-triol (1, Figura 5). Em seguida efetuaram-se estudos sobre os substituintes no anel catecólico, concluindo que o grupo eletroatrator nitro na posição 3 do catecol é indispensável para a inibição, uma vez que reduz a nucleofilia do grupo hidroxilo, diminuindo a susceptibilidade do inibidor à reação de 0-metilação enzimática [8]. De facto, o nitrocatecol já era o farmacóforo usado para desenvolver os inibidores competitivos da COMT desde que estes mostraram ter relevância clínica (segunda geração) [6]. Confirmado o farmacóforo, a atenção voltou-se para o anel de pirazol, no qual se utilizaram substituintes no átomo de nitrogénio adjacente ao catecol, observando-se que grupos fenílicos nesta posição inibiam totalmente a atividade enzimática. Adicionando um grupo fenilo orto ao nitrocatecol e inserindo um grupo carbonilo entre o átomo de nitrogénio e um p-tolueno (2, Figura 5), obteve-se uma inibição mais moderada. Os compostos com melhor atividade inibitória foram testados na fase seguinte [8].

A partir deste ponto, os compostos foram testados in vivo em ratos através de administração oral e, após poucas horas, determinou-se a atividade da COMT nos seus fígados. Procedeu-se à otimização do centro heterocíclico, alterando as posições relativas, número e tipo de heteroátomos, e ainda variando o tamanho deste anel. No fim foram testados os anéis de oxadiazole e detetou-se um aumento da inibição, em especial com o 3-fenil-5-(3-nitrocatecol-5-il)-1,2,4-oxadiazole (3, Figura 5) que, neste ensaio, se mostrou equipotente à tolcapona. Adicionalmente, este composto também demonstrou ser seletivo para a COMT no fígado, em detrimento da existente no cérebro [8].
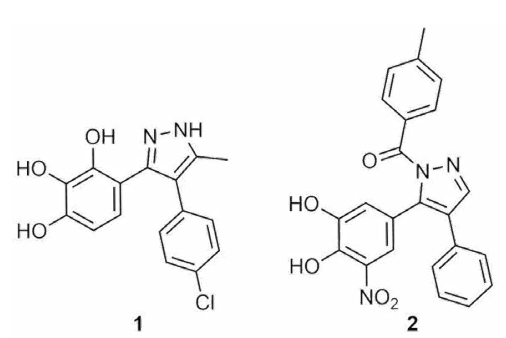<smiles>O=[N+]([O-])c1cc(-c2nc(-c3ccccn3)no2)cc(O)c1O</smiles><smiles>O=[N+]([O-])c1cc(-c2nc(-c3ccc[n+]([O-])c3)no2)cc(O)c1O</smiles><smiles>Cc1c(Cl)c(C)[n+]([O-])c(Cl)c1-c1noc(-c2cc(O)c(O)c([N+](=O)[O-])c2)n1</smiles> 
Os estudos da relação estrutura-atividade (SAR) continuaram com a otimização do substituinte da posição 3 do anel de oxadiazole. Além da atividade enzimática da COMT, também foram tidos em conta a lipofilia dos compostos $(\log P)$ e a viabilidade celular (teste de toxicidade in vitro em linhas celulares de neuroblastoma de ratinho). Os primeiros substituintes tinham por base o grupo fenilo: os que tinham substituintes halogenados eram potentes, mas muito lipofílicos e tóxicos; os que tinham substituintes mais polares não eram tóxicos, mas demonstraram ser inibidores muito pouco potentes. Por conseguinte, o grupo fenilo foi excluído e foram testados substituintes mais hidrofílicos com anéis heterocíclicos saturados e depois anéis heteroaromáticos. Embora muitos compostos tenham sido testados, a maioria era tóxica ou demonstrava uma fraca inibição da COMT, sendo que o substituinte mais promissor foi o 2-piridil (4, Figura 5). Testou-se, em seguida, o efeito dos substituintes neste anel, contudo, os compostos obtidos apresentaram elevada toxicidade [8].

Apesar da anterior toxicidade, o átomo de nitrogénio do anel foi oxidado e chegou-se a um $\mathrm{N}$-óxido de piridina não substituído (5, Figura 5) que demonstrou não ser tóxico. Contudo, este é muito polar, o que pode justificar uma fraca absorção por via oral e, consequentemente, uma fraca inibição da COMT. Assim, foram testados vários substituintes, como $\mathrm{CF}_{3}$, metilo ou $\mathrm{Cl}$, em diversas posições do anel. Por fim, obteve-se a opicapona (Figura 5), que é muito potente e bastante segura, pelo que se prosseguiu para os testes farmacológicos [8].

\section{Estudos computacionais}

Num estudo de modelação de um farmacóforo para inibidores da COMT com base em ligandos conhecidos para a referida enzima, a opicapona (OPC) foi a molécula que melhor mapeou as características químicas do farmacóforo selecionado nesse estudo (Figura 6) [9].
Na ausência de uma estrutura cristalográfica da COMT com os seus cofatores e a OPC, existem estudos de docking molecular nos quais são identificadas as interações estabelecidas entre ligando e recetor. A Figura 7 demonstra que a OPC interage com o $\mathrm{Mg}^{2+}$, o SAM e com os resíduos de aminoácidos Trp38, Met40, Asp141, Trp143, Lys144, Asp169, Asn170, Pro174, Glu199 e Arg201 [9].

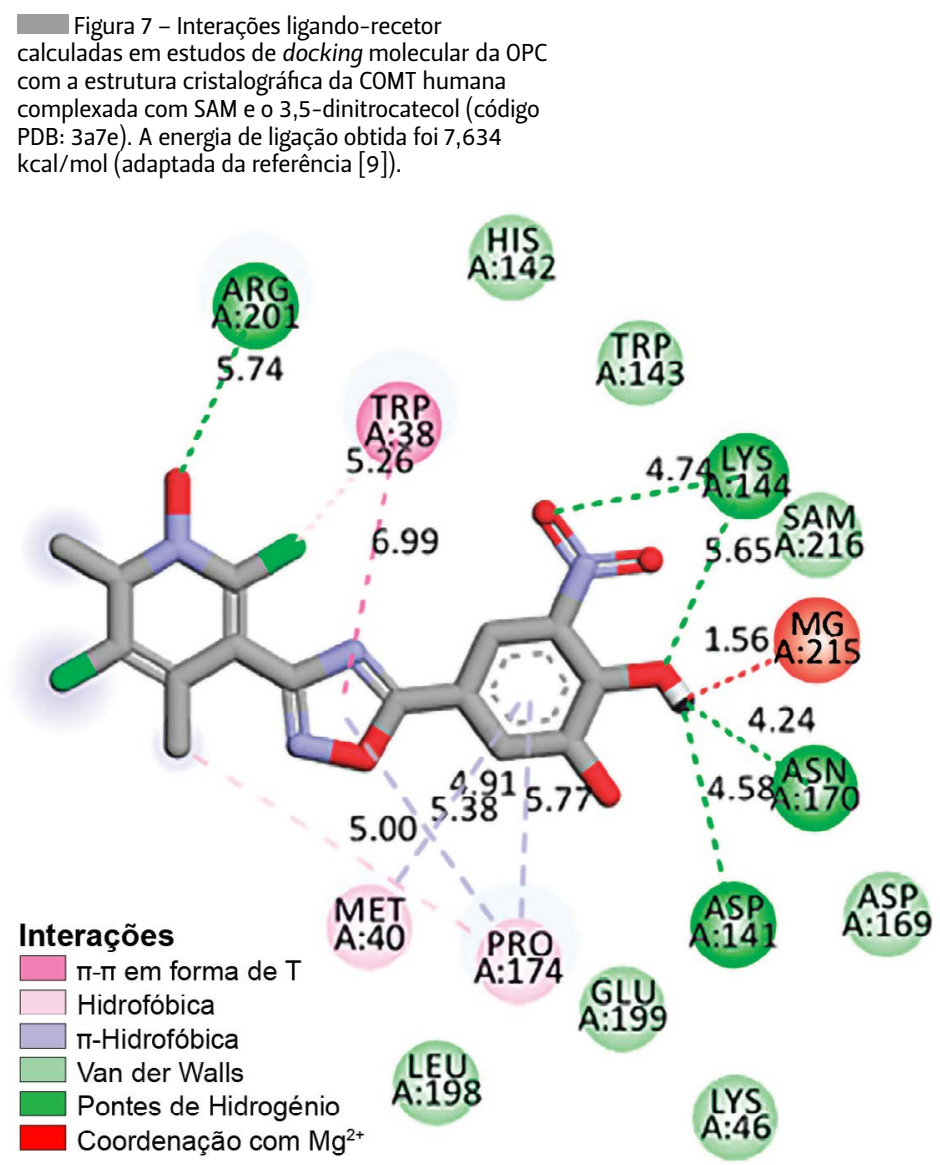

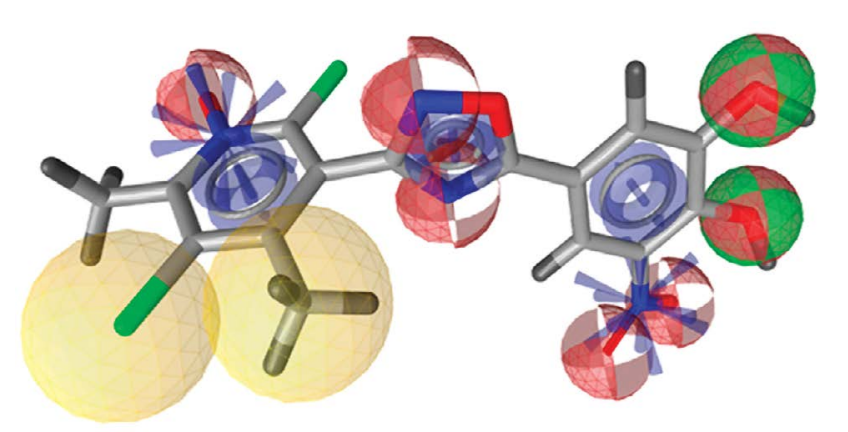

Figura 6 - Modelo de farmacóforo da OPC gerado no programa LigandScout (representações em 3D e 2D). Este farmacóforo inclui como características: a vermelho sete aceitadores de pontes de hidrogénio $(\mathrm{HBA})$, a verde dois dadores de pontes de hidrogénio (HBD), a amarelo duas regiões hidrofóbicas $(\mathrm{H})$, a azul três anéis aromáticos (PI) e com asteriscos azuis duas áreas ionizadas (adaptada da referência [9]).

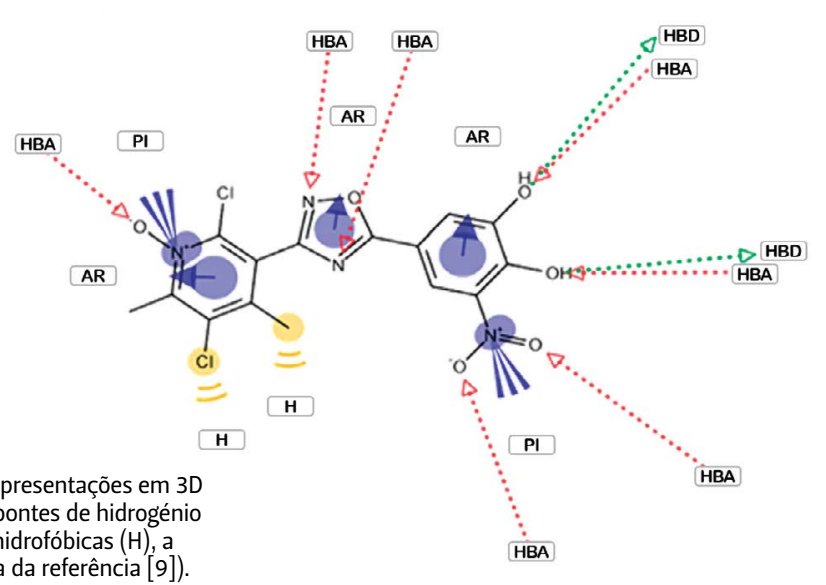

HBA 
As propriedades farmacocinéticas (ADMET) da OPC também foram calculadas: 413,17 g/mol de massa molecular, três liğações rotáveis e dezanove rígidas, uma flexibilidade de 0,14, dez aceitadores de pontes de hidrogénio (HBA) e dois dadores (HBD), um coeficiente de partição $(\log P)$ de 3,42, um coeficiente de distribuição $(\log D)$ de 1,93, uma solubilidade em água $\left(\log S_{a q}\right)$ de $-4,7$ e a área superficial polar topológica (TPSA) de $150,33 \AA$ [9]. Tendo em conta estas previsões, a OPC aparenta ter potencial para ser administrada oralmente com base nas regras empíricas de Lipinski e no filtro de Ghose (refratividade não considerada). Todavia, quando ponderadas as regras de Veber (biodisponibilidade oral), a OPC excede um pouco o critério de que a TPSA não deve ultrapassar os $140 \AA$.

\section{Ensaios clínicos}

Ensaios pré-clínicos realizados com ratos revelam que a OPC inibe a COMT periférica durante 8 a 24 horas e que, 6 horas após a administração, os valores de $E D_{50}$ eram superiores a 1,4 mg/kg. Uma única dosagem de OPC em ratos resulta no aumento dos níveis de L-DOPA no plasma (e redução do 3-OMD) 2 a 24 horas após a administração. Adicionalmente, a OPC não demonstrou efeitos citotóxicos quando avaliada clinicamente em hepatócitos humanos [10].

Num estudo realizado com administrações de OPC (10 a 1200 mg) por via oral a voluntários masculinos saudáveis, determinou-se que a extensão da sua exposição sistémica é diretamente proporcional à dose administrada, podendo decrescer se for administrada após uma refeição rica em calorias e gordura. Este composto é solúvel na corrente sanguínea e não atravessa a barreira hematoencefálica [4].

A 3-0-sulfatação da OPC (6, Figura 8) nos intestinos e no fígado pela sulfotransferase SULT1A1 (enzima de fase II que catalisa a O-sulfatação de compostos fenólicos [5]) aparenta ser a via metabólica preferencial para a OPC. 0 único metabolito ativo é a amina, a forma reduzida do grupo $\mathrm{N}$-óxido da OPC (9, Figura 8), que também pode ser encontrado no plasma, mas é minoritário (menos de 15\%). 0 metabolito 3-0-metilado (7, Figura 8) pode ser detetado em quantidades vestigiais em doses desde $400 \mathrm{mg}$. Por fim, o metabolito 3-0-glucuronidado (8, Figura 8) é o único que é detetado na urina e corresponde apenas a $2 \%$ da dose de OPC administrada, pelo que a via de excreção preferencial para esta e todos os seus restantes metabolitos é a bílis $[4,11]$.<smiles>Cc1c(Cl)c(C)[n+]([O-])c(Cl)c1-c1noc(-c2cc(OS(=O)(=O)O)c(O)c([N+](=O)[O-])c2)n1</smiles><smiles>COc1cc(-c2nc(-c3c(C)c(Cl)c(C)[n+]([O-])c3Cl)no2)cc([N+](=O)[O-])c1O</smiles><smiles>Cc1c(Cl)c(C)[n+]([O-])c(Cl)c1-c1noc(-c2cc(OC3OC(C(=O)O)C(O)C(O)C3O)c(O)c([N+](=O)[O-])c2)n1</smiles><smiles>Cc1nc(Cl)c(-c2noc(-c3cc(O)c(O)c([N+](=O)[O-])c3)n2)c(C)c1Cl</smiles>

Figura 8 - Principais metabolitos da OPC.

0 tempo de meia-vida $\left(t_{1 / 2}\right)$ da OPC no plasma é relativamente curto ( 0,8 a 3,2 horas), todavia, o $t_{1 / 2}$ da OPC associada ao seu alvo biológico COMT é consideravelmente superior (61,6 horas). Este longo tempo de atividade in vivo deve-se à sua elevada afinidade $\left(K_{i}=17 \times 10^{-12} \mathrm{M}\right)$ e reduzida constante de dissociação do complexo COMT-OPC $\left(K_{d}=3 \times 10^{-14} \mathrm{M}\right)$, resultando num longo tempo de existência do complexo $\left(k_{\text {off }}=10^{-7} \mathrm{~s}^{-1}\right)$, apesar da elevada atividade enzimática $\left(k_{\text {cat }}=10^{-4} \mathrm{~s}^{-1}\right)$. Esta propriedade permite uma única administração diária $[4,10,11]$. A inibição máxima da COMT pela OPC depende da dose (36,1\% para 10 mg e $100 \%$ a partir de 200 mg), já a duração da inibição é praticamente independente da dose administrada [4].

Durante os estudos clínicos de fase II, os efeitos da OPC na farmacocinética da L-DOPA, relativamente ao grupo placebo, revelaram que a exposição à L-DOPA aumentou 25,54 e $66 \%$, relativamente a doses administradas de 5, 15 e 20 mg, respetivamente. Os tratamentos foram, na generalidade, bem tolerados e seguros [12].

\section{Síntese do fármaco}

A síntese da opicapona foi patenteada pela BIAL (Figuras 9 e 10) e inicia-se com a obtenção dos compostos intermediários $\mathbf{1 5}$ e $\mathbf{1 8}$ [13].

A preparação do composto $\mathbf{1 5}$ inicia-se com a formação do composto 12 a partir da condensação da cianoacetamida $\mathbf{1 1}$ com a acetilacetona $\mathbf{1 0}$ em metanol e morfolina a $65^{\circ} \mathrm{C}$. 0 produto formado é arrefecido em acetonitrilo e posteriormente é adicionado cloreto de sulfurilo deixando à temperatura ambiente para originar o composto 13. 0 composto 14 é sintetizado a partir da reação do produto anterior com cloreto de fosforilo e cloreto de tetrabutilamónio em diclorometano a $85^{\circ} \mathrm{C}$. 0 composto $\mathbf{1 5}$ é então obtido por reação de $\mathbf{1 4}$ 
com hidroxilamina na presença de 1,10-fenantrolina mono-hidratada numa mistura de metanol e água a uma temperatura de 70 a $80{ }^{\circ} \mathrm{C}[13]$.

0 composto 18 é preparado via reação de nitração no anel aromático do ácido vanílico (16) com ácido nítrico (originando o composto $\mathbf{1 7}$ ), seguida de uma reação adição-eliminação com cloreto de tionilo em dioxano ou em diclorometano com dimetilformamida (usado como catalisador), a uma temperatura entre 75 e $85^{\circ} \mathrm{C}$ [13].

Figura 9 - Síntese patenteada da OPC (primeiros passos).<smiles>CC(=O)CC(C)=O</smiles>

10<smiles>N#CCC(N)=O</smiles>

11<smiles>CO[C@@H](C)[C@@H](O)[C@@H](O)OC</smiles>

12<smiles>Cc1[nH]c(=O)c(C#N)c(C)c1Cl</smiles>

14<smiles>C=C(N)c1c(Cl)nc(C)c(Cl)c1CC(C)O</smiles>

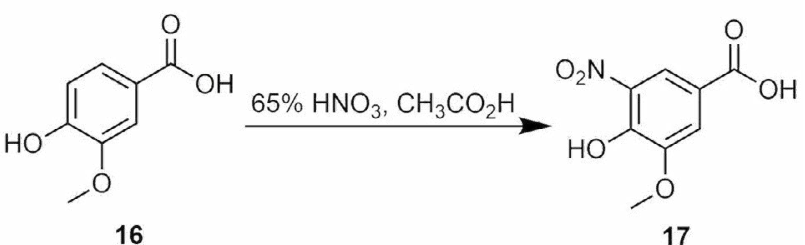

16

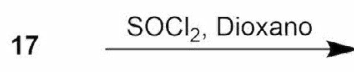

18

A síntese prossegue através de uma reação de cicloadição dos compostos $\mathbf{1 5}$ e $\mathbf{1 8}$, com uma mistura de dimetilacetamida, tetra-hidrofurano ou dioxano na presença de piridina a uma temperatura de 100 a $120{ }^{\circ} \mathrm{C}$. A estas reações seguiu-se a $\mathrm{N}$-oxidação do composto 19, utilizando peróxido de hidrogénio como agente oxidante (adicionado através de um complexo de ureia), sendo este passo realizado numa solução em diclorometano e na presença do anidrido trifluoroacético (formando o composto $\mathbf{2 0}$ ). Por fim, a OPC é obtida pela desproteção de um grupo hidroxilo a partir da sua forma metilada, sendo utilizados como reagentes o ácido de Lewis $\mathrm{AlCl}_{3}$, piridina (usada como base e solvente) e uma solução de $\mathrm{N}$-Metilpirrolidona a temperaturas entre 55 e $65^{\circ} \mathrm{C}[13]$.

15

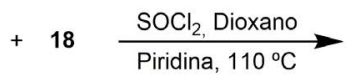<smiles>COc1cc(-c2nc(-c3c(Cl)nc(C)c(Cl)c3C)no2)cc([N+](=O)[O-])c1O</smiles>

19<smiles>COc1cc(-c2nc(-c3c(C)c(Cl)c(C)[n+]([O-])c3Cl)no2)cc([N+](=O)[O-])c1O</smiles>

20 1. $\mathrm{AlCl}_{3}, \mathrm{~N}$-Metilpirrolidona, Piridina 2. $\mathrm{HCl}(\mathrm{aq})$

Opicapona Figura 10 - Síntese patenteada da OPC (passos finais)

\section{Conclusão}

Muitos compostos têm vindo a ser sintetizados e testados para auxiliar no tratamento da DP. A opicapona é um destes compostos, demonstrando propriedades farmacológicas promissoras e resultados favoráveis nos ensaios clínicos efetuados. Após estes estudos, a OPC foi considerada como um fármaco relativamente eficaz e seguro, sendo produzida industrialmente e comercializada sob o nome Ogentys.

Desde que este fármaco saiu para o mercado, demonstrou uma redução dos efeitos secundários durante o tratamento da DP comparativamente aos outros fármacos mencionados. A OPC tem sido um dos inibidores da COMT mais eficientes no tratamento desta doença, embora apenas seja usada em 20 a 25\% dos pacientes com DP. Futuramente as empresas de produção deste fármaco pretendem executar novos testes clínicos de modo a estudar novas formas de administração e tratamentos utilizando diversos tipos de compostos [14].

\section{Agradecimentos}

Este trabalho foi desenvolvido no âmbito da unidade curricular de Química Medicinal do Mestrado em Química Bioorgânica do Departamento de Química da Faculdade de Ciências e Tecnologia da Universidade Nova de Lisboa, sob o imprescindível apoio e supervisão da Professora Doutora Maria Manuel B. Marques. 


\section{Referências}

[1] A. Blochberger, S. Jones, Clin. Pharm. 2011, 3, 361-366.

[2] C. Klein, A. Westenberger, Cold Spring Harb. Perspect. Med. 2012, 2, 363-369. DOI: 10.1101/cshperspect.a008888.

[3] S. Gallegos, C. Pacheco, C. Peters, C. Opazo, L. G. Aguayo, Front. Neurosci. 2015, 9, 1-11. DOI: 10.3389/fnins.2015.00059.

[4] L. Almeida, J.-F. Rocha, A. Falcão, P. N. Palma, A. I. Loureiro, R. Pinto, M. J. Bonifácio, L. C. Wright, T. Nunes, P. Soares-da-Silva, Clin. Pharmacokinet. 2013, 52, 139-51. DOI: 10.1007/s40262-012-0024-7.

[5] C. M. F. Lopes, Opicapone Sulfation: Sulfotransferase Isoforms Characterization. Dissertação de Mestrado, Faculdade de Ciências da Universidade do Porto, 2013.

[6] L. E. Kiss, P. Soares-da-Silva, J. Med. Chem. 214, 57, 8692-8717. DOI: 10.1021/jm500572b.

[7] D. A. Learmonth, L. E. Kiss, P. Soares-da-Silva, Int. Rev. Neurobiol. 2010, 95 119-162. DOI: 10.1016/b978-0-12-381326-8.00006-5.

[8] J. Fischer, C. Klein, W. E. Childers, Successful Drug Discovery, Volume 3, Wiley-VCH, Weinheim, 2018, 319-339.
[9] C. N. Patel, J. J. George, K. M. Modi, M. B. Narechania, D. P. Patel, F. J. Gonzalez, H. A. Pandya, J. Biomol. Struct. Dyn. 2018, 36, 3938-3957. DOI: 10.1080/07391102.2017.1404931.

[10] M. J. Bonifácio, L. Torrão, A. I. Loureiro, P. N. Palma, L. C. Wright, P. Soares-daSilva, Br. J. Pharmacol. 2015, 172, 1739-1752. DOI: 10.1111/bph.13020.

[11] J.-F. Rocha, L. Almeida, A. Falcão, P. N. Palma, A. I. Loureiro, R. Pinto, M. J. Bonifácio, L. C. Wright, T. Nunes, P. Soares-da-Silva, Br. J. Clin. Pharmacol. 2013, 76, 763-775. DOI: 10.1111/bcp.12081.

[12] J. J. Ferreira, J.-F. Rocha, A. Falcão, A. Santos, R. Pinto, T. Nunes, P. SoaresDa-Silva, Eur. J. Neurol. 2015, 22, 815-e56. DOI: 10.1111/ene.12666.

[13] Domenico Russo, Laszlo Erno Kiss, Jorge Bruno Reis Wahnon, David Alexander Learmonth, Tibor Eszenyi, Axel Zimmermann, Bjoern Schlummer, Michael Kreis, Klaus Reiter, Chemical compound useful as intermediate for preparing a catechol-0-methyltransferase inhibitor. WO 2013/089573 Al, 2019.

[14] M. Fabbri, J. J. Ferreira, A. Lees, F. Stocchi, W. Poewe, E. Tolosa, O. Rascol, Movement Disord. 2018, 33, 1528-1539. DOI: 10.1002/mds.27475.

\section{Marcos Bento}

É licenciado em Química pela Faculdade de Ciências - Universidade de Lisboa. Em 2018 ingressou no Mestrado em Química Bioorgânica da Faculdade de Ciências e Tecnologia - Universidade NOVA de Lisboa. A sua tese abrange química inorgânica, catálise e eletroquímica. ma.bento@campus.fct.unl.pt ORCID.org/0000-0001-6000-7659

\section{* Miriam Colaço}

É licenciada em Bioquímica pela Faculdade de Ciências e Tecnologia - Universidade NOVA de Lisboa, tendo ingressado no Mestrado em Química Bioorgânica da mesma instituição. Encontra-se a finalizar a tese que engloba síntese, fotoquímica e química supramolecular. mr.colaco@campus.fct.unl.pt CIÊNCIA ID: 5D1A-A69B-49AD

\section{$>$}

\section{Rúben Guerreiro}

É licenciado em Bioquímica pela Universidade da Beira Interior. Em 2018 ingressou no Mestrado em Química Bioorgânica na Faculdade de Ciências e Tecnologia - Universidade NOVA de Lisboa, estudos que interrompeu para aceitar uma proposta profissional como Analista de Microbiologia na Hovione.

andreruben@live.com.pt

CIÊNCIA ID: A81C-E7BF-48D5 